\title{
ANALISIS FAKTOR YANG MEMPENGARUHI TEKANAN DARAH TENAGA KERJA YANG TERPAPAR PANAS TAHUN 2017
}

Kharisma Amalia, Erna Triastuti, Suprijandani

\begin{abstract}
ABSTRAK
Tenaga kerja yang terpapar panas dapat mengalami peningkatan tekanan darah. Peningkatan tekanan darah juga bisa disebabkan oleh karakteristik individu tenaga kerja yaitu usia,masa kerja, status gizi, dan kebiasaan merokok. Penelitian ini bertujuan mempelajari pengaruh faktor yang mempengaruhi tekanan darah tenaga kerja yang terpapar panas.

Jenis penelitian ini adalah penelitian analitik observasional dengan desain cross sectional. Prosedur pengumpulan data dilakukan dengan observasi lingkungan kerja, wawancara tenaga kerja, pengukuran tekanan darah (sistolik dan diastolik) sebelum dan sesudah bekerja, dan pengukuran tekanan panas dilakukan dengan metode Indeks Suhu Basah dan Bola (ISBB). Jumlah sampel sebanyak 36 tenaga kerja diambil secara simple random sampling. Selanjutnya data yang sudah dikumpulkan dianalisis dengan uji wilcoxon signed ranks dan uji kendall's tau.

Hasil penelitian pada pengukuran tekanan darah menunjukkan $77,8 \%$ tenaga kerja mengalami peningkatan tekanan darah sesudah bekerja dan sebagian besar $(91,7 \%)$ tenaga kerja terpapar tekanan panas $>28^{\circ} \mathrm{C}$. Sebagian besar $(72,2 \%)$ berusia $>$ 40 tahun dengan masa kerja $(86,1 \%)>5$ tahun, dan $(58,3 \%)$ memiliki status gizi normal, serta $(69,4 \%)$ memiliki kebiasaan merokok.

Kesimpulan dari penelitian ini adalah ada pengaruh antara tekanan panas, karakteristik individu (usia, masa kerja, dan kebiasaan merokok) terhadap peningkatan tekanan darah, $p<0,05$. Tidak ada pengaruh antara status gizi terhadap peningkatan tekanan darah, $p>0,05$. Disarankan perlu melakukan pengendalian teknik dengan menambahkan ventilasi alami berupa jendela, memperbaiki local exhaust ventilation yang tidak berfungsi dengan baik, serta menambahkan exhaust fan. Memberikan jam istirahat yang sesuai dengan SOP perusahan yang telah ditentukan dan memberikan tes kesehatan awal dan berkala. Alat pelindung diri khususnya baju kerja sebaiknya terbuat dari bahan katun.
\end{abstract}

Kata Kunci : Karakteristik Individu, Tekanan Darah, Terpapar Panas.

\section{PENDAHULUAN}

Pembangunan industri merupakan salah satu tujuan pembangunan nasional yang memiliki dampak positif yaitu terhadap peningkatan pendapatan dan pemerataan pembangunan. Disisi lain industri memiliki faktor risiko bahaya dalam menghasilkan produksinya. Salah satu sumber pencemaran terbesar di lingkungan yaitu berasal dari industri yang menggunakan mesin besar dengan menghasilkan suhu yang tinggi dalam proses produksinya dan beban kerja yang diterima tenaga kerja sehingga dapat menyebabkan iklim kerja yang panas dan gangguan kesehatan seperti peningkatan tekanan darah.

Keselamatan dan Kesehatan Kerja (K3) merupakan program yang telah dijalankan di beberapa perusahaan besar yang bertujuan untuk melindungi seluruh tenaga kerja dan menciptakan kondisi lingkungan kerja yang nyaman, sehingga dapat mendukung produktivitas kerja yang dihasilkan. Pada saat bekerja memerlukan sistem pengawasan yang cukup besar agar terhindar dari bahaya pada manusia yaitu penyakit akibat kerja serta gangguan kesehatan dan kematian. PT. Jatim Taman Steel, Mfg merupakan salah satu perusahaan yang bergerak dibidang produksi baja. Perusahaan ini mempunyai faktor lingkungan yang dapat menyebabkan gangguan kesehatan pada tenaga kerja. Adapun faktor lingkungan yang paling berpengaruh pada perusahaan ini yaitu tekanan panas yang berasal dari mesin yang digunakan untuk proses pembuatan baja dengan suhu mencapai $1600^{\circ} \mathrm{C}$ serta beban kerja yang tinggi. Lingkungan kerja yang berpotensi panas terdapat pada bagian Scrap 18 ton 
dan 20 ton, EAF (Electrical Arc Furnace) 18 ton dan 20 ton, LF (Ladle Furnace), VD (Vacum Degassing), CCM (Continous Casting Machine), dan BI (Billet Inspection).

Berdasarkan hasil survei pendahuluan yang telah dilakukan di PT. Jatim Taman Steel, Mfg diketahui bahwa iklim kerja pada bagian EAF 20 ton mencapai $33,9^{\circ} \mathrm{C}$, LF $31,5^{\circ} \mathrm{C}$, dan CCM $32,2^{\circ} \mathrm{C}$. EAF 18 ton tidak dilakukan pengukuran karena pada saat itu mesin belum beroperasi dengan optimal maka tekanan panas di lingkungan kerja tersebut belum homogen dan scrap juga belum dilakukan pengukuran karena pada saat itu kegiatan sangat padat dan tidak memungkinkan untuk diambil sampel. Tenaga kerja bagian Scrap 18 dan 20 ton, EAF 18 dan 20 ton, LF, dan CCM banyak yang mengalami kepanasan saat bekerja, kelelahan bekerja, dan cepat merasakan haus. Tujuan penelitian ini adalah mempelajari pengaruh faktor yang dianalisis dengan tekanan darah tenaga kerja yang terpapar panas.

\section{METODE PENELITIAN}

Jenis penelitian ini merupakan analitik observasional dengan pendekatan cross sectional. Populasi penelitian adalah seluruh operator pada ruang steel making yang terpapar panas dengan jumlah 43 tenaga kerja. Sampel penelitian sebanyak 36 tenaga kerja. Teknik pengambilan sampel menggunakan simple random sampling. Variabel bebas penelitian ini adalah tekanan panas dan karakteristik individu (usia, masa kerja, status gizi, dan kebiasaan merokok) serta variabel terikatnya yaitu tekanan darah. Proses pengumpulan data dengan data primer yaitu melakukan observasi dengan pengamatan langsung lingkungan kerjanya, pengukuran tekanan panas, pengukuran tekanan darah sebelum dan sesudah terpapar panas, dan wawancara pada tenaga kerja dengan lembar kuesioner. Data sekunder diperoleh dari data perusahaan dan data tenaga kerja. Data yang sudah diperoleh kemudian dianalisis dengan uji wilcoxon signed ranks dan uji kendall's tau untuk mengetahui pengaruh faktor yang dianalisis terhadap peningkatan tekanan darah.

\section{HASIL DAN PEMBAHASAN}

Penelitian ini menggunakan 6 bagian sebagai sampel pengukuran tekanan panas yaitu Scrap 18 dan 20 ton, EAF 18 dan 20 ton, LF, dan CCM. Konstruksi dinding ruang steel making terbuat dari seng dengan pembatas antara bagian 1 dengan bagian lain yaitu hanya dibatasi oleh mesin produksi. Sumber panas dari mesin produksi dengan suhu mencapai $1600^{\circ} \mathrm{C}$. Sistem ventilasi menggunakan ventilasi alami berasal dari jendela dengan luas kurang dari $15 \%$ luas lantai dan pintu utama, ventilasi buatan yaitu kipas angin dan local exhaust ventilation namun tidak berfungsi dengan baik.

Nilai ambang batas tekanna panas diperoleh dengan menentukan beban kerja berdasarkan hasil observasi yang telah dilakukan serta perhitungan jam kerja sebagai berikut :

$$
\begin{gathered}
\frac{\text { waktu terpapar panas }}{\text { jam kerja }} \times 100 \% \\
\frac{6}{7,5} \times 100 \%=80 \%
\end{gathered}
$$

Maka NAB ISBB $28^{\circ} \mathrm{C}$ dengan beban kerja sedang dan pengaturan waktu jam kerja setiap jam $80 \% \quad$ (75\%-100\%). 
Tabel 1

HASIL PENGUKURAN TEKANAN PANAS

\begin{tabular}{ccc}
\hline No & Bagian & Tekanan Panas $\left({ }^{\circ} \mathbf{C}\right)$ \\
\hline 1 & Scrap 18 ton & 28,9 \\
\hline 2 & Scrap 20 ton & 28,0 \\
\hline 3 & EAF 18 ton & 29,1 \\
\hline 4 & EAF 20 ton & 28,6 \\
\hline 5 & LFVD & 29,6 \\
\hline 6 & CCM & 29,6 \\
\hline
\end{tabular}

Berdasarkan Peraturan Menteri Tenaga Kerja dan Transmigrasi Nomer 13 Tahun 2011 tentang Nilai Ambang Batas Faktor Fisika dan Faktor Kimia di tempat Kerja yaitu $\leq 28^{\circ} \mathrm{C}$ untuk beban kerja sedang dengan pengaturan waktu kerja $75 \%-100 \%$ bekerja. Hasil distribusi frekuensi faktor yang mempengaruhi tekanan darah tenaga kerja dapat dilihat pada tabel 2 dibawah ini.

Tabel 2

DISTRIBUSI FREKUENSI FAKTOR YANG MEMPENGARUHI TEKANAN DARAH TENAGA KERJA

\begin{tabular}{|c|c|c|c|c|}
\hline NO & VARIABEL & KRITERIA & FREKUENSI & PERSENTASE \\
\hline \multicolumn{5}{|c|}{ Faktor lingkungan } \\
\hline \multirow{2}{*}{1} & \multirow{2}{*}{ Tekanan panas } & $\leq 28^{\circ} \mathrm{C}$ & 3 & 8,3 \\
\hline & & $>28^{\circ} \mathrm{C}$ & 33 & 91,7 \\
\hline \multicolumn{5}{|c|}{ Karakteristik Individu } \\
\hline \multirow{2}{*}{2} & \multirow{2}{*}{ Usia } & $\leq 40$ tahun & 10 & 27,8 \\
\hline & & $>40$ tahun & 26 & 72,2 \\
\hline \multirow{2}{*}{3} & \multirow{2}{*}{ Masa kerja } & $\leq 5$ tahun & 5 & 13,9 \\
\hline & & $>5$ tahun & 31 & 86,1 \\
\hline \multirow{4}{*}{4} & \multirow{4}{*}{ Status gizi } & Kurus & 2 & 5,6 \\
\hline & & Normal & 21 & 58,3 \\
\hline & & Gemuk & 8 & 22,2 \\
\hline & & Sangat gemuk & 5 & 13,9 \\
\hline \multirow{2}{*}{5} & \multirow{2}{*}{ Kebiasaan merokok } & Tidak merokok & 11 & 30,6 \\
\hline & & Merokok & 25 & 69,4 \\
\hline
\end{tabular}


Berdasarkan tabel diatas diketahui bahwa dari 36 tenaga kerja sebagian besar $(91,7 \%)$ berada di lingkungan kerja yang ISBB nya $>28^{\circ} \mathrm{C}$. Frekuensi usia dari 36 tenaga kerja sebagian besar $(72,2 \%)$ memiliki usia $>40$ tahun. Frekuensi masa kerja sebagian besar $(86,1 \%)$ memiliki masa kerja $>5$ tahun. Frekuensi status gizi sebagian besar $(58,3 \%)$ memiliki status gizi normal. Frekuensi kebiasaan merokok sebagian besar $(69,4 \%)$ memiliki kebiasaan merokok. Rerata tekanan darah sistolik sebelum terpapar panas 121,39 $\mathrm{mmHg}$ dan tekanan darah sistolik sesudah terpapar panas 130,83. Rerata tekanan darah diastolik sebelum terpapar panas $76,11 \mathrm{mmHg}$ dan tekanan darah diastolik sesudah terpapar panas 82,5 $\mathrm{mmHg}$.

Berdasarkan hasil uji beda Wilcoxon Signed Ranks terhadap tekanan darah sistolik maupun diastolik sebelum dan sesudah terpapar panas, memperoleh ( $p$ $<0,05$ ), maka Ho di tolak menunjukkan bahwa ada perbedaan tekanan darah sistolik maupun diastolik sebelum dan sesudah terpapar panas.

Dari 36 tenaga kerja sebagian besar $(77,8 \%)$ dengan tekanan darah meningkat sesudah terpapar panas, lebih jelasnya dapat dilihat tabel 3 sebagai berikut ini.

Tabel 3

DISTRIBUSI FREKUENSI TEKANAN DARAH

TENAGA KERJA SESUDAH BEKERJA

\begin{tabular}{clcc}
\hline \multirow{2}{*}{ No } & Tekanan Darah & Frekuensi & Persentase \\
& & & \\
\hline 1 & Normal & 8 & 22,2 \\
\hline 2 & Meningkat & 28 & 77,8 \\
\hline & Total & 36 & 100 \\
\hline
\end{tabular}

Hasil pengujian hipotesis yang menyatakan ada pengaruh antara faktor yang dianalisis dengan tekanan darah tenaga kerja yang terpapar panas dapat dilihat pada tabel 4 berikut ini.

Tabel 4

DISTRIBUSI TEKANAN DARAH TENAGA KERJA MENURUT FAKTOR YANG MEMPENGARUHI

\begin{tabular}{|c|c|c|c|c|c|c|c|c|}
\hline \multirow{3}{*}{ NO } & \multirow{3}{*}{ VARIABEL } & \multirow{3}{*}{ KRITERIA } & \multicolumn{4}{|c|}{ TEKANAN DARAH } & \multirow{3}{*}{ TOTAL } & \multirow{3}{*}{$\mathbf{P}$} \\
\hline & & & \multicolumn{2}{|c|}{ NORMAL } & \multicolumn{2}{|c|}{ MENINGKAT } & & \\
\hline & & & $f$ & $\%$ & $f$ & $\%$ & & \\
\hline \multicolumn{9}{|c|}{ Faktor Lingkungan } \\
\hline \multirow{2}{*}{1} & Tekanan & $\leq 28^{\circ} \mathrm{C}$ & 3 & 37,5 & 0 & 0 & 3 & \multirow{2}{*}{0,001} \\
\hline & panas & $>28^{\circ} \mathrm{C}$ & 5 & 62,5 & 28 & 100 & 33 & \\
\hline \multicolumn{9}{|c|}{ Karakteristik Individu } \\
\hline \multirow{2}{*}{2} & \multirow{2}{*}{ Usia } & $\leq 40$ tahun & 6 & 75 & 4 & 14,3 & 10 & \multirow{2}{*}{0,001} \\
\hline & & $>40$ tahun & 2 & 25 & 24 & 85,7 & 26 & \\
\hline \multirow{2}{*}{3} & \multirow{2}{*}{ Masa kerja } & $\leq 5$ tahun & 4 & 50 & 1 & 3,6 & 5 & \multirow{2}{*}{0,001} \\
\hline & & $>5$ tahun & 4 & 50 & 27 & 96,4 & 31 & \\
\hline \multirow{4}{*}{4} & \multirow{4}{*}{ Status gizi } & Kurus & 0 & 0 & 2 & 7,1 & 2 & \multirow{4}{*}{0,134} \\
\hline & & Normal & 3 & 37,5 & 18 & 64,3 & 21 & \\
\hline & & Gemuk & 4 & 50 & 4 & 14,3 & 8 & \\
\hline & & $\begin{array}{l}\text { Sangat } \\
\text { gemuk }\end{array}$ & 1 & 12,5 & 4 & 14,3 & 5 & \\
\hline \multirow[t]{2}{*}{5} & \multirow{2}{*}{$\begin{array}{c}\text { Kebiasaan } \\
\text { merokok }\end{array}$} & $\begin{array}{c}\text { Tidak } \\
\text { merokok }\end{array}$ & 6 & 75 & 5 & 17,9 & 11 & \multirow{2}{*}{0,002} \\
\hline & & Merokok & 2 & 25 & 23 & 82,1 & 25 & \\
\hline
\end{tabular}


Berdasarkan tabel diatas dapat diketahui bahwa dari 36 tenaga kerja $100 \%$ berada di lingkungan kerja yang ISBB nya $>28^{\circ} \mathrm{C}$ mengalami peningkatan tekanan darah. Hasil uji kendall's tau dengan $\mathrm{p}<0,05$, maka ada pengaruh tekanan panas terhadap peningkatan tekanan darah tenaga kerja.

Kondisi lingkungan dan upaya pengendalian yang kurang memenuhi syarat yaitu kurangnya ventilasi pada bagian steel making, belum terdapat ruang aklimatisasi yaitu ruang penyesuaian, serta kurangnya jam istirahat.

Menurut Soeripto dalam Fahrurrozi Arfad (2013) tekanan panas disebabkan karena adanya sumber panas yang mempengaruhi lingkungan kerja. Intensitas panas yang tinggi apabila sistem ventilasi di lingkungan kerja tidak bisa mengeluarkan panas yang ada di dalam ruangan. Lingkungan kerja yang tinggi akan menyebabkan beberapa gangguan kesehatan seperti dehidrasi, meningkatkan stres, meningkatkan tekanan darah, meningkatkan denyut nadi, dan penurunan kerja otak.

Berdasarkan hasil diatas dapat dilakukan beberapa pengendalian, untuk mengurangi terjadinya bahaya gangguan kesehatan dan lingkungan kerja yaitu pengendalian teknik seperti penambahan ventilasi alami, pengendalian administratif seperti menambah jam istirahat, melakukan pemeriksaan kesehatan awal dan berkala.

Pada variabel usia sebagian besar $(85,7 \%)$ memiliki usia $>40$ tahun mengalami peningkatan tekanan darah. Hasil uji kendall's tau dengan $p<0,05$, maka ada pengaruh usia terhadap peningkatan tekanan darah tenaga kerja.

Tenaga kerja dengan usia > 40 tahun sebaiknya tidak ditempatkan di lokasi kerja yang panas, karena orang yang memiliki usia tua akan lebih lambat keluar keringatnya dibandingkan dengan orang yang lebih muda (Siswanto, 1990).

Hal ini disebabkan karena tekanan darah lebih tinggi apabila usia semakin tua. Tekanan sistolik akan meningkat sejalan dengan peningkatan usia, sedangkan tekanan diastolik meningkat sampai dengan usia 55 tahun dan setelah itu mengalami penurunan (Albina Bare Telan, 2012).

Pada variabel masa kerja sebagian besar $(96,4 \%)$ memiliki masa kerja $>5$ tahun mengalami peningkatan tekanan darah. Hasil uji kendall's tau dengan $p<0,05$, maka ada pengaruh masa kerja dengan peningkatan tekanan darah tenaga kerja.

Menurut Suma'mur (2009) seseorang yang bekerja dalam waktu yang lama di lingkungan kerja yang memiliki faktor fisik diatas nilai ambang batas akan menyebabkan terjadinya penurunan kemampuan organ tubuh dalam menjalankan fungsinya, perubahan tersebut bisa meliputi penurunan fungsi otak karena kurangnya pasokan oksigen, melebarnya pembuluh darah, menurunnya respon kulit terhadap rangsangan, meningkatnya aliran darah serta meningkatnya irama jantung.

Pada variabel status gizi sebagian besar $(64,3 \%)$ memiliki status gizi normal mengalami peningkatan tekanan darah. Hasil uji kendall's tau dengan $\mathrm{p}>0,05$, maka tidak ada pengaruh status gizi dengan peningkatan tekanan darah tenaga kerja.

Menurut Albina Bare Telan (2012) apabila status gizi tergolong sangat gemuk atau obesitas dapat menyebabkan gangguan kesehatan seperti terjadinya peningkatan tekanan darah.

Pada variabel kebiasaan merokok sebagian besar $(82,1 \%)$ memiliki kebiasaan merokok mengalami peningkatan tekanan darah. Hasil uji kendall's tau dengan $\mathrm{p}<0,05$, maka ada pengaruh kebiasaan merokok dengan peningkatan tekanan darah tenaga kerja.

Kebiasaan merokok merupakan salah satu kebiasaan buruk terjadinya peningkatan tekanan darah, yang menyebabkan pembuluh darah dibeberapa bagian tubuh akan menyempit dan membutuhkan tekanan lebih tinggi agar darah dapat mengalir ke alat-alat tubuh dengan jumlah tetap. Sedangkan jantung harus memompa darah lebih kuat, sehingga tekanan pada pembuluh darah mengalami peningkatan. 


\section{Kesimpulan}

1. Tenaga kerja PT. Jatim Taman Steel, Mfg ruangsteel making sebagian besar $(72,2 \%)$ berusia $>40$ tahun dengan masa kerja $(86,1 \%)>5$ tahun, dan $(58,3 \%)$ memiliki status gizi normal, serta $(69,4 \%)$ memiliki kebiasaan merokok.

2. Tenaga kerja mengalami peningkatan tekanan darah sesudah terpapar panas sebanyak 28 tenaga kerja dengan persentase $77,8 \%$.

3. Tenaga kerja sebagian besar $(91,7 \%)$ terpapar panas $>28^{\circ} \mathrm{C}$.

4. Ada pengaruh antara tekanan panas terhadap peningkatan tekanan darah.

5. Ada pengaruh antara karakteristik individu (usia, masa kerja, dan kebiasaan merokok) terhadap peningkatan tekanan darah dan tidak ada pengaruh antara status gizi terhadap peningkatan tekanan darah.

\section{Saran}

1. Bagi PT. JatimTaman Steel, Mfg

Perusahaan sebaiknya memperbaiki pengendalian yang kurang memenuhi syarat meliputi pengendalian teknik dengan menambahkan ventilasi alami berupa jendela dengan ukuran $15 \%$ luas lantai, memperbaiki local exhaust ventilation agar berfungsi dengan baik, dan menambahkan exhaust fan.

Pengendalian administratif memberikan jam istirahat yang sesuai dengan SOP perusahan yang telah ditentukan dan memberikan tes kesehatan awal dan berkala. Alat pelindung diri khususnya baju kerja sebaiknya terbuat dari bahan katun.

2. Bagi peneliti lain

Peneliti lain diharapkan menambahkan variabel yang diteliti seperti beban kerja dengan pemeriksaan menggunakan kalorimeter agar mengetahui beban yang diterima setiap tenaga kerja. Serta menambahkan variabel dari faktor lingkungan seperti kebisingan, apabila kebisingan di lokasi sangat tinggi.

\section{DAFTAR PUSTAKA}

Arfad, Fahrurrozi, Makmur Sinaga, dan Gerry Silaban, 2013. Perbedaan Tekanan Darah Sebelum dan Sesudah Terpapar Panas pada Pekerja BagianBottling Process PT. Sinar Sosro Deli Serdang Tahun 2013.

http://download.portalgaruda.org. 23 Oktober 2016.

Peraturan Menteri Tenaga Kerja dan Transmigrasi Republik Indonesia Nomor 13 Tahun 2013 Tentang Nilai Ambang Batas Faktor Fisika dan Faktor Kimia di Tempat Kerja.

Siswanto, A, 1991. Tekanan panas. Surabaya, Balai Hiperkes dan Keselamatan Kerja Jawa Timur: 3336.

Suma'mur, 2009. Higiene Perusahaan dan Kesehatan Kerja (HIPERKES). Jakarta, Sagung seto: 151-165.

Telan, Albina Bare, 2012. Pengaruh Tekanan Panas Terhadap Perubahan Tekanan Darah dan Denyut Nadi pada Tenaga Kerja Industri Pandai Besi di Desa Hadipolo Kecamatan Jekulo Kabupaten Kudus Jawa Tengah. http://eprints.undip.ac.id. $\quad 10$ November 2016. 